\title{
VOLUMES OF SUB-LEVEL SETS AND THE DECAY OF OSCILLATORY INTEGRALS
}

\author{
TA LÊ LOI
}

Abstract. In this paper, we present estimates for the volumes of sub-level sets and the decay of oscillatory integrals with phase functions in a family of functions definable in an o-minimal structure with compact domains.

Mathematics subject classification (2020): Primary 14P15, 26D15; Secondary 32B20, 42A38.

Keywords and phrases: Sub-level set, oscillatory integral, o-minimal structure, Hölder-Łojasiewicz inequality.

\section{REFERENCES}

[1] V. I. Arnold, S. M. Gusein-Zade And A. N. VArchenko, Singularities of differentialble maps, Vol. II, Monographs in Mathematics, vol. 83, Birkhäuser Boston Inc., MA, 1988.

[2] M. Coste, An Introduction to O-minimal Geometry, Dottorato di Ricerca in Matematica, Dip. Mat. Pisa. Instituti, 2000.

[3] A. CARbery, M. Christ And J. Wright, Multidimensional van der Corput and sublevel set estimates, J. Amer. Math. Soc. 12, no. 4, 1999, 981-1015.

[4] R. Cluckers, G. Comte, D. J. Miller, J.-P. Rolin And T. Servi, Intergration of oscillarory and subanalytic functions, Duke Math. J. 165, no. 7, 2018, 1239-1309.

[5] R. Cluckers AND D. J. Miller, Bounding the decay of oscillatory integrals with a constructible amplitute function and a globally subanalytic phase functions, J. Fourier Anal. Appl. 22, 2016, 215236.

[6] L. VAN DEN DrIES, Tame Topology and o-minimal Structures, LMS Lecture Notes, Cambridge University Press, 1997.

[7] L. VAn Den DRIES And C. Miller, Geometric Categories and o-minimal Structures, Duke Math. J. 84, no. 2, 1996, 497-540.

[8] H. FEDERER, Geometric measures theory, Springer-Verlag, 1969.

[9] R. M. HARDT, Some analytic bounds for subanalytic sets, Differential geometric control theory, (Houghton, Mich., 1982): 259-267, Progr. Math. 27, Birkhauser Boston, Boston, Mass., 1983.

[10] K. KURDYKA, On the gradients of functions definable in o-minimal structures, Ann. Inst. Fourier (48) 3, 1998, 769-783.

[11] T. L. LoI, Lojasiewicz inequalities in o-minimal structures, Manuscripta Math., 150, 2016, 59-72.

[12] T. L. LoI, Hölder-Lojasiewicz inequalities for volumes of tame objects, Math. Z., 2021, https://doi.org/10.10007/s00209-021-02696-9.

[13] T. L. LoI, Stratification of families of functions definable in o-minimal structures, Acta Mat. Vietnamica 27, no. 2, 2002, 239-244.

[14] T. L. LoI, Verdier Stratifications and Thom Stratifications in O-minimal Structures, Illinois J. Math. 42, no. 2, 1998, 347-356.

[15] T. L. Loi AND P. PHIEn, Bounds of Hausdorf measures of tame sets, Acta Math. Vietnam 39, 2014, 637-647, doi:10.1007/s40306-014-0090-z.

[16] M. Shiota, Geometry of subanalytic and semialgebraic sets, Progress in Mathematics vol. 150, Birkhäuser, 1997.

[17] P. SpeISSEGGE, Fiberwise properties of definable sets and functions in o-minimal structures, Manuscipta math. 86, 1995, 283-291. 
[18] E. M. Stein, Harmonic Analysis, Priceton U. Press, Priceton, 1993. 